\title{
Popliteal Artery Injury after Low-Energy Knee Dislocation in the Obese
}

Veger HTC, Borger van de Burg B, Visser MJT and Joosten Hedeman

Department of Vascular Surgery, Leiden University Medical Centre, Netherlands

*Corresponding author: H T C Veger, Department of Vascular Surgery, Leiden University Medical Centre, Netherlands, Tel: +31642171672; E-mail: htcveger@hotmail.com

Rec date: Nov 23, 2014; Acc date: May 19, 2015; Pub date: May 21, 2015

Copyright: $\odot 2015$ Veger HTC, et al. This is an open-access article distributed under the terms of the Creative Commons Attribution License, which permits unrestricted use, distribution, and reproduction in any medium, provided the original author and source are credited.

\begin{abstract}
The last decade an increasing number of Low Energy Knee Dislocations (LEKD)in obese patients have been reported in the orthopaedic and vascular surgery literature. Vascular repair in the obese can be technically challenging and is associated with more perioperative complications than in the no obese. Using a percutaneous approach to blunt injury of the popliteal artery due to LEKD in the obese patient where even more extensive soft tissue injury may complicate open repair is a novel way to avoid incisions and manipulation of the injured ischemic lower extremity.
\end{abstract}

Keywords: Popliteal injury; Vascular injury; Knee dislocation; Obese

\section{Introduction}

Knee dislocations (KD) are uncommon, constituting less than $0.5 \%$ of joint dislocations and vary from $1 / 10,000$ to $1 / 100,000$ on admission per institution per year [1]. Vascular injury often involves the popliteal artery with reported rates up to 50\% [2]. The popliteal vessels are relatively fixed at the adductor hiatus and fascial arch of the soleus making them vulnerable during $\mathrm{KD}[2,3]$. The mechanism of injury for $\mathrm{KD}$ can be divided into high-energy (HE) dislocation (motor vehicle accidents, crush injuries) and low-energy (LE) dislocation (falls, slips). The last decade an increasing number of LEKDs in obese patients have been reported in the orthopedic and vascular surgery literature $[2,4]$. The LEKD in obese patients frequently occur with minimal trauma. These patients are more difficult to diagnose because of body size and the inherent low-velocity nature of their injury. Vascular repair or amputation in the obese can be technically challenging and is associated with more perioperative complications than in the no obese [5].

We report two cases of obese women with LEKDs suffering a blunt popliteal artery injury and discuss both the open and endovascular method for treating this potential limb threatening condition.

\section{Case description}

\section{Patient A}

A 26-year-old female was brought to the emergency department with a painful left knee after her dog pulled her over on the beach. Apart from morbid obesity (body mass index $45 \mathrm{~kg} / \mathrm{m} 2$ ) she had no medical history. Plain radiographs showed an anterior dislocation without signs of fracture. Immediate reposition was performed. A secondary series of plain radiographs showed adequate reposition without signs of fracture. Re-evaluation showed that the left foot was cooler than the right. CT angiogram showed an occluded left popliteal artery with patent tibial and peroneal arteries. Exploration of the popliteal artery was challenging due to the large amount of soft tissue although performed by longitudinal medial incision. A reversed venous saphenous vein graft harvested from the contralateral extremity restored the arterial flow to the distal popliteal artery. Clinical course was uncomplicated.

\section{Patient B}

A 65-year-old female was brought into the emergency department after falling over in her campervan. Due to morbid obesity physical examination (body mass index $47 \mathrm{~kg} / \mathrm{m} 2$ ) showed no obvious deformities, but the lower left leg was pale compared to the right leg. Plain radiographs showed an anterior dislocation of the knee without signs of fractures. After reposition a CT angiogram revealed a popliteal artery dissection with local thrombosis and minimal flow to the lower leg.

Considering the large amount of soft tissue in this patient an endovascular approach was chosen to treat the popliteal artery dissection. Access was obtained in the Left Superficial Femoral Artery (SFA) and a 6 French sheath was placed. Five thousand units of intravenous heparin were administered. The angiogram revealed thrombotic occlusion due to a dissection and thrombosis of the popliteal (segment P 1 to 3) (Figure 1).

Multiple attempts to pass the dissection using a 0.035-inch angle-tip guidewire were not successful. A retrograde approach was chosen although due to low flow state only the tibial posterior artery could be identified. The approach to the tibial posterior artery was not possible in supine position due to patient's morbid obesity. In prone position a 4 French sheath in the left tibial posterior artery was inserted. A selective angiogram was performed below the dissection to delineate runoff in the tibial vessels. The posterior tibial, anterior tibial and peroneal arteries were patent to the ankle. The dissection was passed with a 0.016-inch guidewire. Prone position made it impossible to pick up the 0.016 -inch guidewire in the 6 French sheath in the SFA. The 4 French sheath in the Left tibial posterior artery was changed to a 6 French sheath. A Supera Veritas self-expanding nitinol stent $(6 \mathrm{~mm} 80$ $\mathrm{mm}$, Boston Scientific) was placed in the tibioperoneal truncus and popliteal artery (Figure 2). This stent type is characterized by being extremely flexible and kink resistant. Completion angiography showed a patent popliteal artery with anterior tibial and peroneal artery runoff 
(Figure 3). The posterior tibial artery was locally occluded at the insertion site of the 6 French sheath.

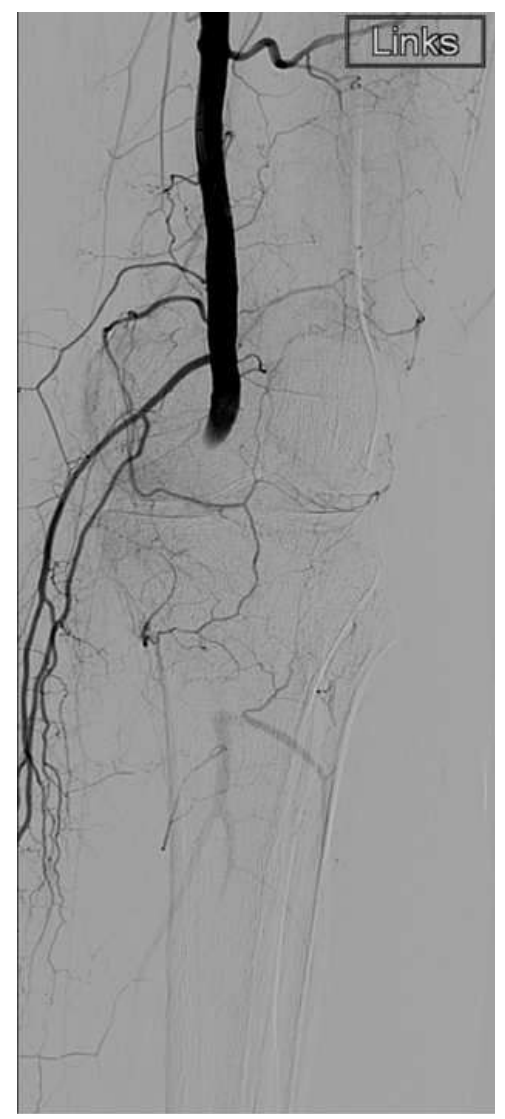

Figure 1: Patient B: The angiogram of the left lower extremity revealed thrombotic occlusion due to a dissection and thrombosis of the popliteal (segment P 1 to 3 ).

\section{Discussion}

Increasing obesity rate may result to an increasing number of LEKD as the above cases illustrate. Severely obese patients with LEKD are even more at risk for vascular injury with reported incidence up to $50 \%[3,6]$. Obese women are more prone for LEKD compared to men [7]. Anterior dislocations usually produce traction trauma to the popliteal artery as it stretches into the intercondylar notch often resulting in intimal tears. These flaps can progress to thrombosis which can completely occlude the artery. Collateral circulation around the knee can maintain distal pulses until soft-tissue swelling occludes this flow resulting in an ischaemic extremity. An ABI of $<0.9$ has yielded sensitivities of $95-100 \%$ in the detection of clinically significant popliteal artery damage [1]. Additional imaging is needed; an arterioangiogram, CT-angiogram or an MR-angiogram [2]. The gold standard approach to blunt popliteal artery injury has been immediate open repair in the acute ischemic lower extremity as illustrated in patient A $[3,4]$. Endovascular approaches may beneficial over open repair especially in the obese patient by avoiding the zone of soft tissue injury while repairing the arterial injury. The disadvantage of the endovascular approach could be distal embolic events. The endovascular approach is reasonable in ischemic lower extremities with blunt popliteal artery injury for which the time from injury is short ( $<6$ hours), thereby allowing time for conversion to a standard open procedure, if necessary.

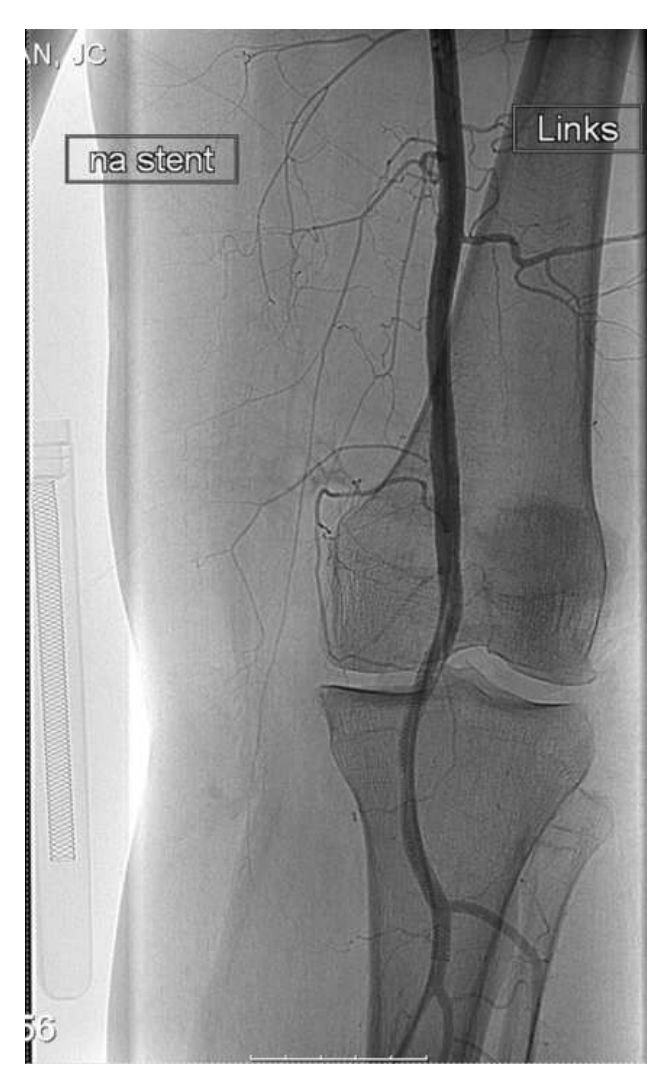

Figure 2: Patient B: A Supera Veritas self-expanding nitinol stent (6 $\mathrm{mm} 80 \mathrm{~mm}$, Boston Scientific) was placed in the tibioperoneal truncus and popliteal artery.

\section{Endovascular Technique}

The preferred endovascular procedure should start with antegrade ipsilateral access in the Common Femoral Artery (6 French sheath). If the dissection could not be passed by the guidewire a retrograde access in the anterior or posterior tibial artery can be obtained (4 French sheath). Retrograde passing the popliteal dissection with a 0.016 -inch guidewire is the next step. One should pick up the 0.016-inch guidewire through the 6 French sheath placed in the CFA. Stent placement can be performed at the injured popliteal section, without further damaging the already heavily stressed soft tissue around the knee. The preferable stent covered or bare in case of endovascular popliteal dissection repair remains debatable. We suspect scenarios like these will become increasingly common, because more than onefifth of all European adults are classified as obese. The general physician must be aware that low energy mechanism and in seemingly trivial mechanisms of injury in the morbidly obese population can result in dislocations with devastating consequences. 
Citation: Veger HTC, Burg BVD, Visser MJT, Hedeman J (2015) Popliteal Artery Injury after Low-Energy Knee Dislocation in the Obese . J Vasc

Page 3 of 3

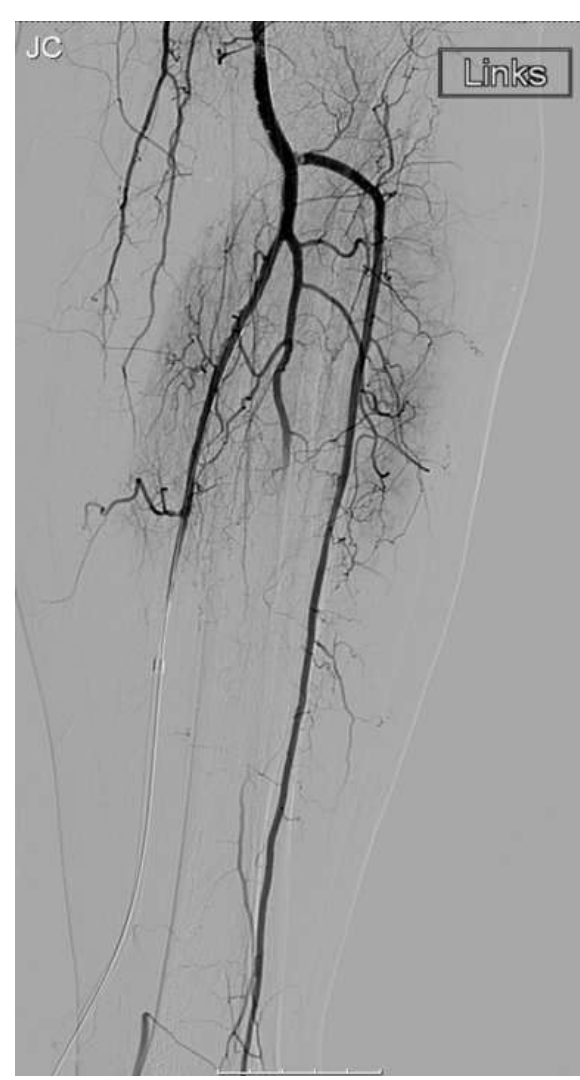

Figure 3: Patient B: Completion angiography showed a patent popliteal artery with anterior tibial and peroneal artery runoff.
In conclusion, using a percutaneous approach to blunt injury of the popliteal artery due to LEKD in the obese patient where even more extensive soft tissue injury may complicate open repair is a novel way to avoid incisions and manipulation of the injured ischemic lower extremity. Long term patency rates of stent placement for blunt popliteal artery injury are unknown and long-term follow-up is required. In younger obese patients stent placement in the distal popliteal artery (P3 segment) should be avoided to preserve a safe landing zone in case a femoro-popliteal bypass might be necessary in the future.

\section{References}

1. Seroyer ST, Musahl V, Harner CD (2008) Management of the acute knee dislocation: the Pittsburgh experience. Injury 39: 710-718.

2. Azar FM, Brandt JC, Miller RH 3rd, Phillips BB (2011) Ultra-low-velocity knee dislocations. Am J Sports Med 39: 2170-2174.

3. Georgiadis AG, Mohammad FH, Mizerik KT, Nypaver TJ, Shepard AD (2013) Changing presentation of knee dislocation and vascular injury from high-energy trauma to low-energy falls in the morbidly obese. J Vasc Surg 57: 1196-1203.

4. Boisrenoult P, Lustig S, Bonneviale P, Leray E, Versier G, et al. (2009) Vascular lesions associated with bicruciate and knee dislocation ligamentous injury. Orthop Traumatol Surg Res 95: 621-626.

5. Hagino RT, DeCaprio JD, Valentine RJ, Clagett GP (1998) Spontaneous popliteal vascular injury in the morbidly obese. J Vasc Surg 28: 458-462.

6. Azar FM, Brandt JC, Miller RH 3rd, Phillips BB (2011) Ultra-low-velocity knee dislocations. Am J Sports Med 39: 2170-2174.

7. Werner BC, Gwathmey FW Jr, Higgins ST, Hart JM, Miller MD (2014) Ultra-low velocity knee dislocations: patient characteristics, complications, and outcomes. Am J Sports Med 42: 358-363. 